\title{
Ensino de Programação em Escolas Públicas: Relato de uma Ação do PET-TI
}

\author{
Letícia Saraiva Chaves $^{1}$, Abilio Castro e Silva ${ }^{1}$, Carla Ilane Moreira Bezerra ${ }^{1}$ \\ ${ }^{1}$ Universidade Federal do Ceará - Campus Quixadá \\ Quixadá - CE - Brasil \\ \{leticiasaraiva, abilio\}@alu.ufc.br \\ carlailanedufc.br
}

\begin{abstract}
This article describes the teaching practices of Programming in Schools developed by the Programa de Educação Tutorial - Tecnologia da Informação (PET-TI). The action of the PET-TI was performed in a high school institution and a technological teaching institution. This action has as main objective to arouse the interest of high school students in the area of Information Technology (IT), as well as disseminate what is computing and its importance, through introductory dynamics programming and logical-mathematical thinking.
\end{abstract}

Resumo. Este artigo descreve as práticas de Ensino de Programação nas Escolas desenvolvidas pelo Programa de Educação Tutorial - Tecnologia da Informação (PET-TI). A ação do PET-TI foi realizada em uma instituição de ensino médio e uma instituição de ensino tecnológico. Essa ação tem como objetivo principal despertar o interesse dos alunos de ensino médio pela área de Tecnologia da Informação (TI), bem como disseminar o que é a computação e a sua importância, por meio de dinâmicas introdutórias a programação e ao pensamento lógico-matemático.

\section{Introdução}

A Tecnologia da Informação (TI) pode ser definida como um agrupamento de atividades e soluções fornecidas através de recursos de computação que tem em vista informações para serem armazenadas, processadas e produzidas. É um recurso amplamente utilizado em diversas áreas, atraindo a atenção de diferentes segmentos da sociedade brasileira, mas principalmente dos jovens, segundo a Pesquisa Nacional por Amostra de Domicílios Contínua (Pnad C), realizada pelo Instituto Brasileiro de Geografia e Estatística (IBGE) (IBGE, 2015).

Como consequência do crescente consumo de TI, a demanda por profissionais da área vem crescendo cada vez mais. Profissões e novas carreiras na área de tecnologia e informática estão surgindo com intensidade para uma demanda que realmente carece de uma boa mão de obra (MATA et al., 2018). Nos últimos anos, a procura por cursos superiores nas áreas relacionadas à computação tem crescido de forma notável. Tanto universidades particulares como públicas têm registrado grande procura por cursos relacionados à computação. Entretanto, apesar da grande procura dos jovens por cursos nesta área, é perceptível o descontentamento de muitos com o curso escolhido, o que causa alto 
VIII Congresso Brasileiro de Informática na Educação (CBIE 2019)

Anais do XXV Workshop de Informática na Escola (WIE 2019)

índice de evasão no decorrer dos semestres destes cursos (DAMASCENO; CARNEIRO, 2018).

Nesse sentido, faz-se necessário apresentar a área para jovens, mostrando o que é computação, a história dos computadores e conceitos de programação que são assuntos situados na base da TI para que mais pessoas tenham conhecimento da área. Além disso, percebe-se que existe uma carência do ensino de computação em escolas de ensino fundamental e médio, principalmente em escolas públicas (TORCATE et al., 2018; ALMEIDA, 2015).

A utilização de novas estratégias de ensino para a Lógica de Programação na educação fundamental pode ser uma forma de diminuir os índices de evasão nos cursos superiores da área de TI, despertar o interesse dos alunos pela área da computação e fazer com que estes alunos desenvolvam melhor o poder cognitivo (NETO et al., 2018).

Portanto, estimular alunos a aprenderem sobre Lógica de Programação aplicada em uma linguagem de programação é interessante para que estes possam conhecer os princípios utilizados em programas, aplicativos e sistemas presentes no dia a dia de muitas pessoas. Com isso, pode-se despertar a procura de novos conhecimentos sobre programação onde, inicialmente, o aprendizado é por curiosidade ou até mesmo divertimento e, posteriormente, pode ser utilizado em uma possível profissão relacionada à TI. Tal iniciativa pode contribuir também para uma melhor utilização de laboratórios nas escolas públicas que em muitos casos são subutilizados (JUNIOR; SCORTEGANGA; FIGUEIREDO, 2018).

Existem várias plataformas que auxiliam no aprendizado de programação como por exemplo a code.org e a RoboGarden ${ }^{1}$ que ensinam programação do zero através de jogos para pessoas que não têm nenhum conhecimento na área.

O presente trabalho pretende mostrar uma forma de ensinar programação para alunos do ensino médio que inclui métodos tradicionais de ensino e também novas práticas, assim como outros trabalhos que se utilizam de outras formas de ensino com o mesmo intuito conforme será apresentado na seção 2. Levar o ensino de programação para jovens pode promover um relacionamento mais inteligente destes com a tecnologia além de melhorar o desempenho em sala de aula.

Este artigo tem como objetivo apresentar uma ação realizado pelo PET-TI sobre o ensino de programação no ensino médio de escolas públicas. Procurando oferecer aulas de introdução à programação como uma maneira de disseminar à computação, despertar o desejo de aprender a programar e desenvolver o pensamento lógico-matemático dos alunos. O público alvo da atividade foram os alunos que cursam o ensino médio e/ou ensino tecnológico, que têm pouca ou nenhuma experiência com computação. No primeiro semestre de 2018 duas instituições participaram da atividade, uma instituição de ensino médio (Escola de Ensino Médio Coronel Virgílio Távora) e uma instituição de ensino tecnológico (Instituto Federal de Educação Ciência e Tecnologia do Ceará (IFCE) - Campus Quixadá) e no primeiro semestre de 2019 apenas o IFCE - Campus Quixadá participou.

Os resultados alcançados pela ação foram muito bons, pois todos os alunos ques-

\footnotetext{
${ }^{1}$ As plataformas podem ser acessadas com os seguintes links respectivamente: studio.code.org/home e robogarden.ca/
} 
VIII Congresso Brasileiro de Informática na Educação (CBIE 2019)

Anais do XXV Workshop de Informática na Escola (WIE 2019)

tionados acharam a proposta do curso interessante e também aprenderam bastante sobre programação e afins, além da frequência dos participantes ter sido considerada satisfatória, o que nos mostrou interesse por parte dos alunos em aprender programação.

\section{Trabalhos relacionados}

Nos últimos tempos os trabalhos envolvendo o ensino de programação vem crescendo. Existem vários trabalhos que promovem o ensino de programação para alunos desde a educação básica e o ensino fundamental. Gomes e Tedesco (2018) é um exemplo de estudo onde após uma pesquisa de três anos uma ferramenta educacional foi desenvolvida e apresentada para auxiliar o ensino de conceitos de programação na educação infantil.

No que se refere à iniciativas de ensino de programação no ensino médio o relato apresentado em Bordin e Quepfert (2018) demonstra que a utilização de ferramentas como o AppInventor, que utiliza programação por blocos, é de grande importância para despertar o interesse dos alunos pela área. No mesmo trabalho foram desenvolvidas oficinas em sete escolas públicas estaduais e percebeu-se que a parceria entre escola pública e instituição de ensino superior (IES) funcionou com sucesso, promovendo a mudança da percepção dos alunos sobre programação.

O ensino de programação vem sendo muito praticado através da robótica educacional, pois os alunos acham mais interessante e se envolvem mais. Trabalhos como o de Neto et al. (2018) utilizam dessa metodologia. No trabalho citado foi utilizado o Arduíno para ensinar programação para alunos do ensino fundamental.

Visto que muitos ingressantes nos cursos de TI têm dificuldade, alguns trabalhos nos últimos cinco anos utilizaram-se de uma técnica mais didática para o ensino de programação e desenvolvimento de habilidades do pensamento computacional que é conhecida como computação desplugada, conforme é apresentado na revisão sistemática da literatura conduzida em Rodrigues, Aranha e Silva (2018). Tal alternativa é adequada para aplicação em escolas que possuem pouca ou nenhuma estrutura de recursos computacionais e permite que se ensine conceitos introdutórios dentro das temáticas da computação.

Visto que muitos ingressantes nos cursos de TI tem dificuldade com Lógica de Programação o projeto citado em Soares, Cavalcanti et al. (2018) visa proporcionar aos alunos de um curso técnico integrado ao ensino médio a oportunidade de adquirir competências relacionadas à programação através de meios lúdicos.

Já em Pinto e Mattos (2019) os autores buscaram técnicas para a introdução de noções de programação de jogos digitais para dispositivos móveis também utilizando a ferramenta AppInventor, onde foi proposto que o estudante realizasse melhores sucessivas em um jogo a partir de uma versão inicial.

A proposta da atividade realizada assemelha-se com a experiência relatada em Bordin e Quepfert (2018), diferindo no fato de que no trabalho citado utilizou-se uma ferramenta de programação por blocos. O público alvo deste trabalho, os alunos do ensino médio, é o mesmo das experiências descritas em Soares, Cavalcanti et al. (2018) e em Pinto e Mattos (2019) entretanto nossa abordagem não utilizou-se da noção de desenvolvimento de jogos. 
VIII Congresso Brasileiro de Informática na Educação (CBIE 2019)

Anais do XXV Workshop de Informática na Escola (WIE 2019)

\section{Metodologia}

O Ensino de Programação nas Escolas é um projeto de extensão do PET-TI que visa ensinar programação para alunos do ensino médio de escolas públicas, onde o contato de tais alunos com o tema abordado é mínimo. Levar esse conhecimento para esses alunos pode despertar o interesse deles em uma área que vem crescendo nos últimos anos e que eles ainda não conheciam, fazendo com que estes tenham a oportunidade de serem apresentados à computação e possam até mesmo considerar esta área dentre suas potenciais áreas para uma escolha profissional.

O grupo de ensino de programação nas escolas buscou, em ambas as instituições, ministrar aulas presenciais (Figura 1), expositivas e práticas em laboratório. Ao esperar que o conhecimento prévio de programação e conceitos afins seria baixo nas turmas, foram elaboradas, para o plano de curso do projeto, aulas que iniciaram desde a apresentação da área de Tecnologia da Informação (TI) até o ensino de estruturas de repetição já em aulas práticas de programação.

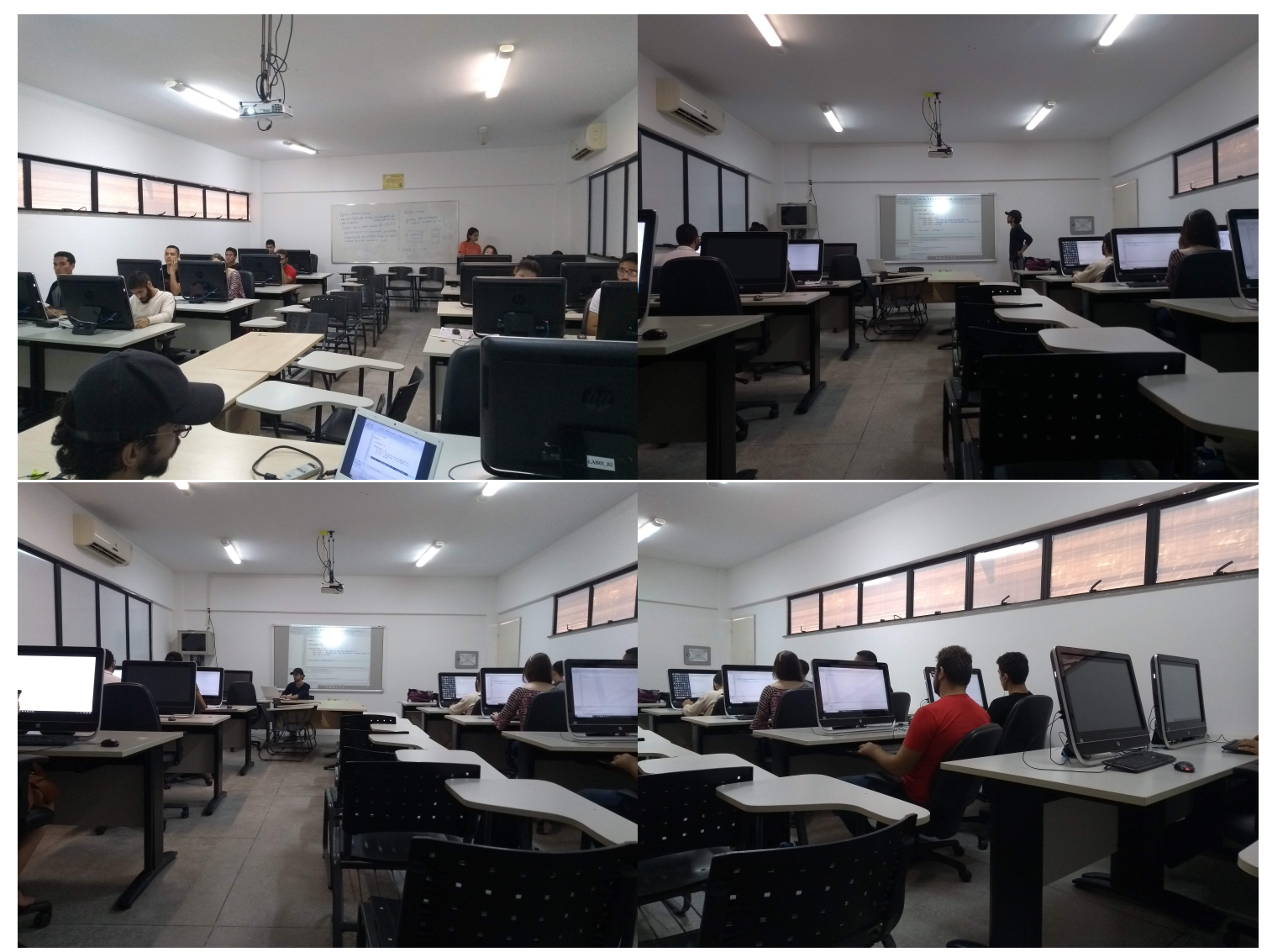

Figura 1. Aulas ministradas durante o projeto em 2019

Por meio de encontros semanais os alunos participaram das aulas na própria instituição em que estudam, desenvolvendo atividades relacionadas ao tema abordado em cada aula. As aulas foram ministradas pelos próprios bolsistas do PET-TI com orientação da tutora. Em 2018 eram apenas três bolsistas, e esses se dividiram para ministrar as aulas nas duas instituições, dois bolsistas ensinaram no IFCE e um outro bolsista na escola, portanto, praticamente não teve acompanhamento das aulas com monitores. Já em 2019 
VIII Congresso Brasileiro de Informática na Educação (CBIE 2019)

Anais do XXV Workshop de Informática na Escola (WIE 2019)

eram cinco bolsistas em apenas uma instituição, o IFCE, logo, o acompanhamento com os alunos era maior, enquanto dois bolsistas ministravam as aulas, os mesmos que ensinaram no ano de 2018, os demais monitoravam os alunos. Em todas as aulas tinham exercícios para que os participantes pudessem praticar o assunto tratado na aula.

O plano de curso desenvolvido e seguido durante o decorrer das aulas apresentouse estruturado em 3 etapas conforme sumarizado na Tabela 1 para o ano de 2018 e na Tabela 2 para o ano de 2019, no final de cada uma delas foi discutido com a turma dúvidas ou assuntos referentes às aulas ministradas. A primeira etapa envolveu aulas teóricas que abordaram a apresentação da área de TI, cursos superiores e carreiras relacionadas, história da computação e estrutura básica do computador. A segunda etapa abordou as primeiras aulas mais próximas da programação, na qual foi apresentado conceito e noções básicas de algoritmo e aulas práticas com a utilização da plataforma code.org, com o objetivo de auxiliar no desenvolvimento do raciocínio lógico para a computação a partir de exercícios simples e práticos oferecidos pela ferramenta. A terceira e última etapa consistiu no ensino e práticas de programação durante todas as aulas, para tal, foi escolhida e apresentada a linguagem de programação $\mathrm{C}++$, pela qual assuntos relacionados, como variáveis, entrada e saída de dados, estruturas de seleção e estruturas de repetição foram abordados durante esta etapa.

\begin{tabular}{|c|c|c|}
\hline Etapa & Tema & Método de Ensino \\
\hline I & Introdução & Aulas Teóricas \\
\hline II & Conceitos Básicos & Práticas no code.org \\
\hline III & Fundamentos de Programação & Aulas Teóricas e Práticas \\
\hline
\end{tabular}

Tabela 1. Etapas do plano de curso realizadas em 2018

\begin{tabular}{|c|c|c|}
\hline Etapa & Tema & Método de Ensino \\
\hline I & Introdução & Aulas Teóricas \\
\hline II & Fundamentos de Programação & Aulas Teóricas e Práticas \\
\hline III & Projeto Final & Práticas \\
\hline
\end{tabular}

Tabela 2. Etapas do plano de curso realizadas em 2019

Os assuntos tratados nas aulas sobre programação foram desde noções básicas de algoritmos, o que é uma variável, quais os tipos de variáveis, até assuntos sobre estruturas condicionais, de repetição e também sobre funções e módulos.

Em todas as aulas expositivas foi usado o auxílio de slides e projeção do código escrito em aula. Algumas dinâmicas de aprendizado foram utilizadas com o objetivo de manter a atenção do aluno para as práticas realizadas em sala, tais como realização de exercícios em dupla, realização de exercícios em lousa e brindes para os alunos mais participativos e assíduos durante todo o curso. No total, foram ofertadas 28 e 18 horas aulas nas turmas da Escola de Ensino Médio Coronel Virgílio Távora e do Instituto Federal do Ceará - Campus Quixadá, respectivamente, sendo divididas em 2 horas aula por semana com o total de 35 alunos alcançados pelo projeto, no primeiro semestre de 2018.

Já no primeiro semestre de 2019, o curso foi dado em aulas expositivas também com auxílio de slides e projeção de código em aula, e o código feito em sala era disponibilizado em um repositório no GitHub para que os alunos tivessem acesso posteriormente 
VIII Congresso Brasileiro de Informática na Educação (CBIE 2019)

Anais do XXV Workshop de Informática na Escola (WIE 2019)

caso não tivessem feito na hora da aula. Foram realizados alguns execícios em sala e para casa também, visando estimular o aluno a pensar em como resolver o problema proposto. Nesse semestre foram ofertadas 18 horas aulas na turma do Instituto Federal do Ceará Campus Quixadá, com 2 horas aula por semana com o total de 15 alunos participando do projeto. A Tabela 3 estrutura melhor essas informações trazendo um resumo sobre todos os dados em relação as horas de curso, número de alunos e monitores em cada instituição.

Durante as aulas, enquanto um bolsista ministrava o conteúdo, os demais auxiliavam os alunos, respondendo suas dúvidas, para que esses pudessem entender o código que estavam produzindo e que no final do curso eles pudessem construir uma pequena aplicação sem ajuda dos ministrantes, apenas utilizando-se dos conhecimentos assimilados durante as aulas.

\begin{tabular}{|c|c|c|c|c|}
\hline Ano & Instituição & Horas de curso & $\mathbf{N}^{\mathbf{0}}$ alunos & $\mathbf{N}^{\mathbf{0}}$ monitores \\
\hline 2018 & IFCE - Campus Quixadá & 18 & 7 & 1 \\
\hline 2018 & E.E.M. Coronel Virgílio Távora & 28 & 28 & 0 \\
\hline 2019 & IFCE- Campus Quixadá & 18 & 15 & 3 \\
\hline
\end{tabular}

Tabela 3. Resumo sobre as informações das atividades.

Na turma de 2019 foi possível realizar a produção de um projeto final dos participantes. Uma aplicação bem simples foi sugerida para que os alunos desenvolvessem utilizando todo o conhecimento adquirido do conteúdo que foi abordado nas aulas. A turma foi dividida em duas equipes para o desenvolvimento da atividade final e ambas as equipes conseguiram concluir o exercício proposto.

\section{Resultados}

Os resultados do Ensino de Programação nas Escolas possuem três perspectivas, uma relacionada a primeira turma de 2018.1, da Escola de Ensino Médio Coronel Virgílio Távora, composta por 28 alunos, outra referente a segunda turma de 2018.1, do Instituto Federal de Educação Ciência e Tecnologia do Ceará - Campus Quixadá, composta por 7 alunos, e a última pertinente a turma de 2019.1, do Instituto Federal de Educação Ciência e Tecnologia do Ceará - Campus Quixadá, composta por 15 alunos.

Com o intuito de captar o interesse dos alunos pelos fundamentos de programação e obter um retorno sobre o curso, foi requisitado aos estudantes de todas as turmas que respondessem um questionário de avaliação onde eles não precisavam se identificar para responder as perguntas.

Em todas as turmas as perguntas iniciais feitas no questionário são relacionadas ao grau de conhecimento e interesse dos participantes sobre programação. A maioria dos alunos da primeira turma de 2018, na Escola de Ensino Médio Coronel Virgílio Távora, (75\%) não conheciam programação, diferente da segunda turma de 2018, no IFCE, onde a maioria dos alunos $(57,1 \%)$ já conheciam algo relacionado a programação. A maior parte dos alunos $(66,7 \%)$ da turma de 2019, no IFCE, já conhecia programação. A maior parte dos alunos, em todas as turmas, demonstraram interesse por programação.

No questionário, também foram realizadas perguntas com o propósito de obter um retorno dos alunos sobre o curso. Todos os alunos (100\%), tanto na primeira turma, 
VIII Congresso Brasileiro de Informática na Educação (CBIE 2019)

Anais do XXV Workshop de Informática na Escola (WIE 2019)

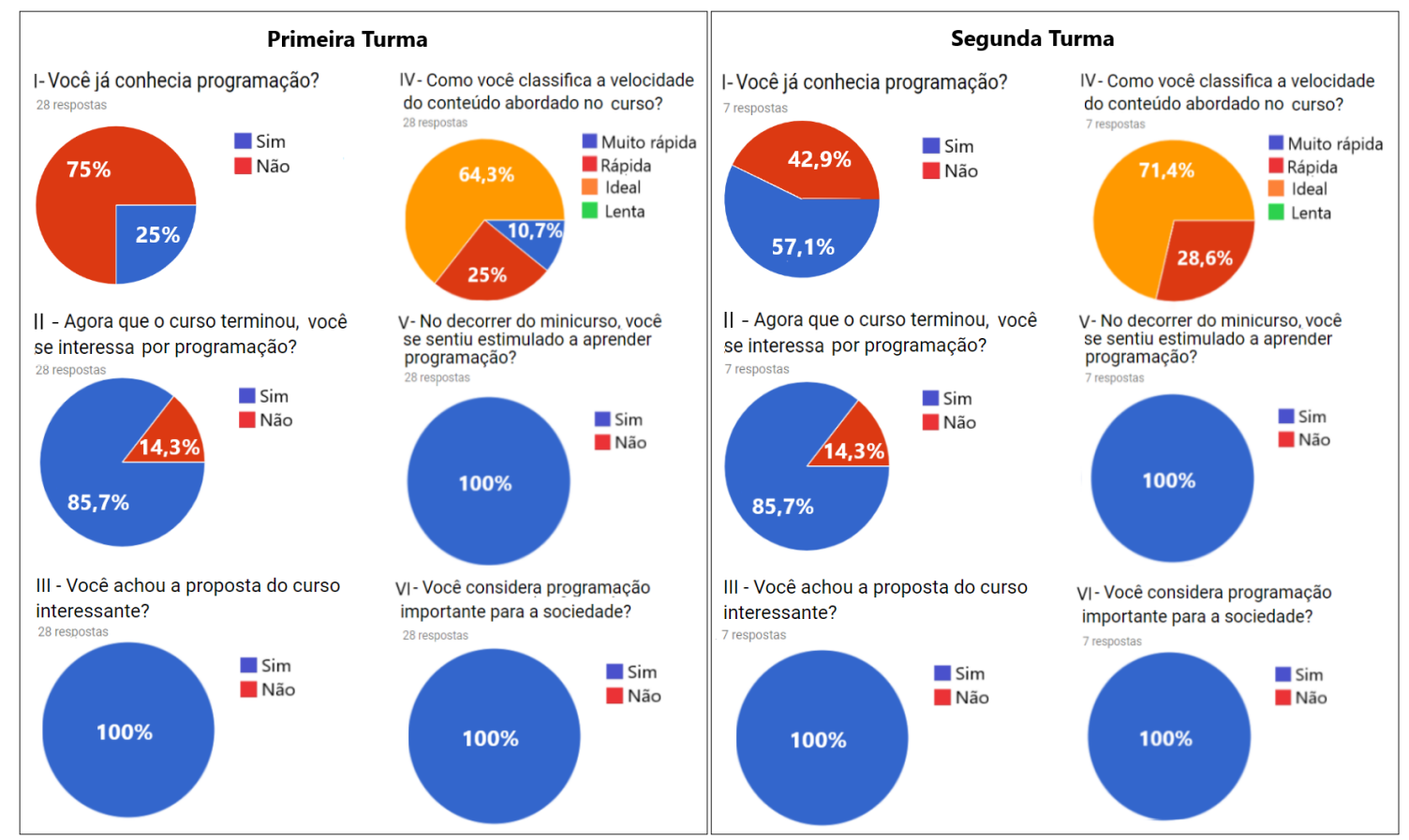

Figura 2. Respostas dos questionários das turmas de 2018.1

quanto na segunda turma de 2018, e também na turma de 2019, acharam interessante a proposta do curso. Alguns alunos declararam que o curso poderia ser um pouco mais aprofundado. Mais da metade dos que responderam ao questionário na primeira turma de $2018(64,3 \%)$, qualificaram a velocidade que o conteúdo foi aplicado como ideal, as outras respostas, relativas à velocidade da abordagem do conteúdo ficaram distribuídas entre rápida $(25 \%)$ e muito rápida $(10,7 \%)$, acreditamos que tenha sido devido ao fato de não ter tido nenhum bolsista como monitor, o que dificulta o processo de acompanhamento dos alunos. Na segunda turma de 2018, mais da metade dos estudantes $(71,4 \%)$ também qualificaram a velocidade que o conteúdo foi aplicado como ideal e os demais $(28,6 \%)$ consideraram a velocidade da abordagem do conteúdo como rápida. Já na turma de 2019 um pouco mais da metade dos alunos $(55,6 \%)$ classificaram a velocidade da abordagem do conteúdo como ideal e a outra parte classificou a velocidade como rápida $(44,4 \%)$, porém conseguiram acompanhar.

As perguntas do questionário direcionadas à experiência dos alunos após entrarem em contato com a programação traz como resultados que todos os alunos (100\%), em ambas as turmas de 2018, se sentiram estimulados a aprender programação. Já na turma de 2019 apenas uma parte dos alunos $(88,9 \%)$ se sentiram estimulados a aprender programação. Todos os alunos, em todas as turmas, consideram programação importante para a sociedade.

$\mathrm{Na}$ turma de 2019, também foi questionado se os alunos participariam de algum projeto envolvendo programação após a conclusão do curso e menos da metade dos alunos $(44,4 \%)$ participaria. Outra pergunta feita na turma de 2019 foi em relação a classificação da metodologia adotada para explicar o conteúdo no curso e boa parte dos alunos $(88,9 \%)$ classifica a metodologia como boa e a outra parte $(11,1 \%)$ classifica como média. Alguns alunos tiveram mais dificuldade em certos assuntos tratados nas aulas, e, eventualmente, 
VIII Congresso Brasileiro de Informática na Educação (CBIE 2019)

Anais do XXV Workshop de Informática na Escola (WIE 2019)

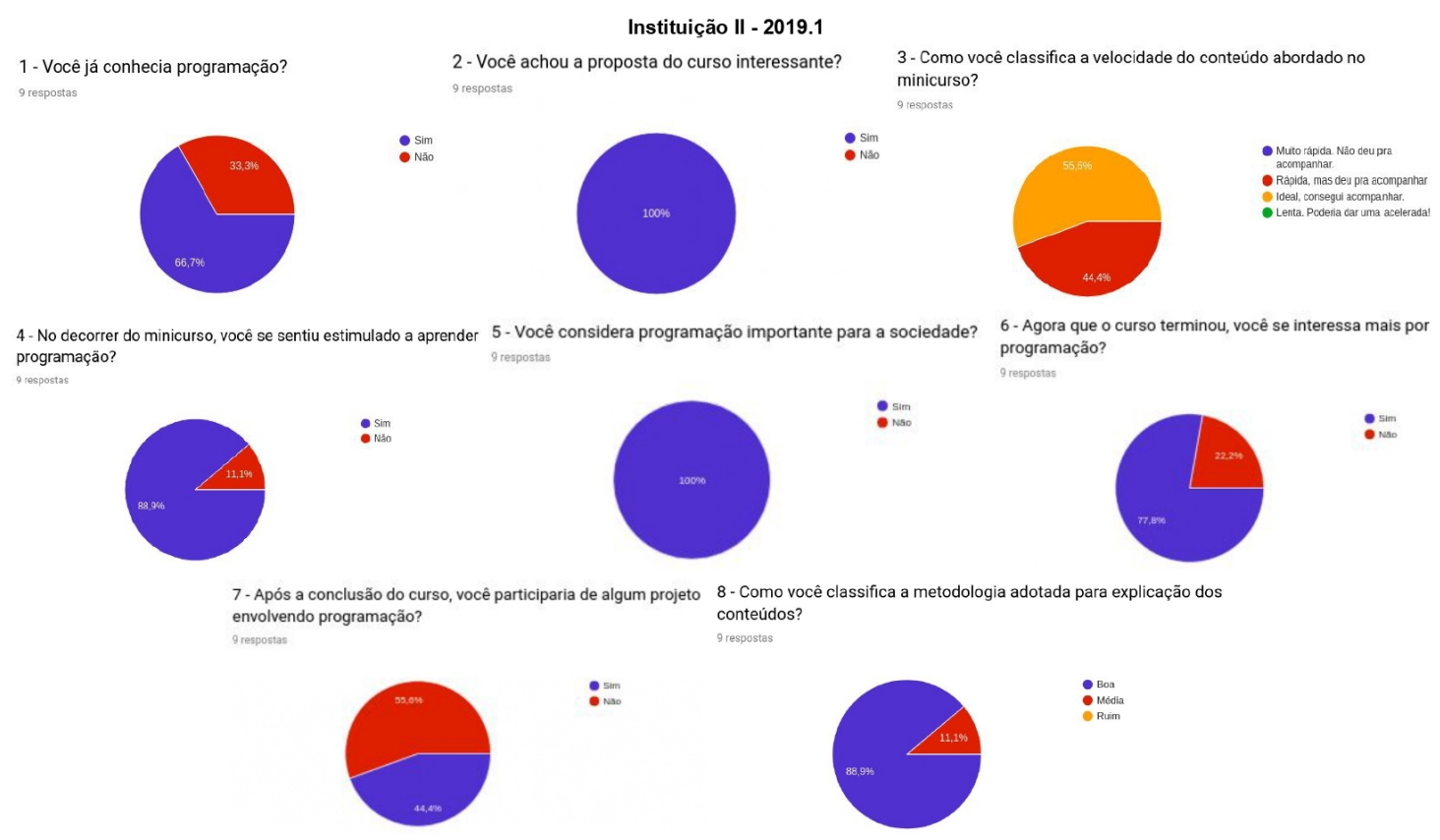

Figura 3. Respostas do questionário da turma de 2019.1

não conseguiam entender muito bem, então um monitor fazia uma explicação somente para ele, com o intuito de que este compreendesse o assunto, mas como a aula continuava a acontecer, o aluno acabava perdendo uma parte da explicação de um assunto mais a frente do qual ele estava tentando entender. Contudo, de maneira geral, os participantes falaram que a metodologia foi boa e sugeriram que o curso pudesse ter uma duração maior.

No geral, os resultados obtidos foram satisfatórios, pois a maioria dos alunos de todas as turmas se interessaram pela proposta do curso e se sentiram estimulados a aprender mais sobre a área. Através das respostas nota-se que os alunos qualificam a programação importante para a sociedade, como observado no decorrer do desenvolvimento da atividade. Todos esses dados podem ser observados nos gráficos da Figura 2 e da Figura 3.

Uma das dificuldades encontradas no decorrer do curso foi o fato de que alguns alunos não conseguiam acompanhar muito bem o conteúdo e precisavam de auxílio o tempo inteiro. Como não tinham muitos bolsistas para auxiliar, alguns alunos recebiam menos atenção. Com mais bolsistas participando do projeto é possível que todos os alunos tenham auxílio suficiente para sanar todas as dúvidas.

\section{Considerações finais}

O ensino de programação depende de diversos fatores, sejam eles relacionados ao meio ou aos alunos. Este trabalho, apresentou um relato da atividade do PET-TI de Ensino de Programação nas Escolas, que possui o intuito de incentivar estudantes do ensino médio a conhecerem os fundamentos e aplicações da programação. Através dos resultados obtidos pelo projeto, é possível concluir, com base na observação dos participantes no decorrer das aulas, que os alunos obtiveram compreensão apropriada dos assuntos tratados ao longo do curso. Consequentemente, observou-se o aumento de seu interesse pelo aprendizado sobre programação. 
VIII Congresso Brasileiro de Informática na Educação (CBIE 2019)

Anais do XXV Workshop de Informática na Escola (WIE 2019)

A experiência adquirida durante o desenvolvimento da atividade também foi valiosa para a equipe responsável por ela, uma vez que esses vivenciaram, na perspectiva de docente, práticas de ensino e aprendizagem. O planejamento das aulas, desenvolvimentos dos componentes auxiliares e a realização de dinâmicas usadas em prol da aprendizagem foram fundamentais para a transmissão e geração de conhecimentos no decorrer da atividade.

Para os participantes do projeto, é ressaltado que os alunos tiveram a oportunidade de conhecer um pouco sobre lógica de programação e como programar. Acredita-se que as aulas do projeto contribuíram significativamente para os estudantes.

Entre as limitações encontradas durante o desenvolvimento dos cursos destaca-se a dificuldade em se encontrar uma velocidade adequada para a apresentação dos conceitos de programação. Tendo em vista que tais conceitos podem parecer fáceis para os ministrantes que já possuem uma experiência na área, porém, representam um desafio de aprendizagem para os alunos do ensino médio. Esta limitação também implica em outro desafio do projeto que é o de conduzir a construção de um projeto final. No ano de 2018 não foi possível realizar tal feito nas turmas ofertadas, muito em razão de que o conteúdo ministrado até as semanas finais do curso não era suficiente para a construção de um produto final, entretanto, para contornar essa situação no ano de 2019 optou-se por propor para os alunos a construção de um projeto final simples mas que abordava todo o conteúdo apresentado.

Como trabalhos futuros, pretende-se aplicar o uso de novas metodologias que possibilitem a realização de um produto final referente aos conceitos e práticas realizadas durante as aulas, sendo este construído coletivamente pelos alunos. Esse produto final poderá ser um jogo digital, aplicativo ou programa de computador, assim os alunos poderiam ter uma visualização de como o que é estudado pode ser aplicado na programação de interfaces gráficas e interações mais elaboradas com o computador. Além disso, também planeja-se realizar a gravação e disponibilização de tutoriais sobre os conteúdos abordados com a finalidade de facilitar o aprendizado dos estudantes em momentos externos às aulas.

\section{Referências}

ALMEIDA, M. Currículo e políticas públicas de tic e educação. Núcleo de Informação e Coordenação do Ponto Br, 2015.

BORDIN, A.; QUEPFERT, W. Projeto de ensino de programação para alunos de ensino médio: Uma análise do cenário e das percepções das oportunidades. In: Anais do Workshop de Informática na Escola. [S.1.: s.n.], 2018. v. 24, p. 205.

DAMASCENO, I.; CARNEIRO, M. Panorama da evasão no curso de sistemas de informção da universidade federal de uberlândia: Um estudo preliminar. In: Brazilian Symposium on Computers in Education (Simpósio Brasileiro de Informática na Educação-SBIE). [S.1.: s.n.], 2018. v. 29, p. 1766.

GOMES, T.; TEDESCO, P. enjoy. et: Um artefato baseado em transmedia storytellling para o ensino de programação para crianças. In: Brazilian Symposium on Computers in 
VIII Congresso Brasileiro de Informática na Educação (CBIE 2019)

Anais do XXV Workshop de Informática na Escola (WIE 2019)

Education (Simpósio Brasileiro de Informática na Educação-SBIE). [S.1.: s.n.], 2018. v. 29, p. 1815.

IBGE, I. Pesquisa nacional por amostra de domicílios: Acesso à internet e à televisão e posse de telefone móvel para uso pessoal. Rio de Janeiro: Ministério do Planejamento, Orçamento e Gestão, 2015.

JUNIOR, A. d. S.; SCORTEGANGA, L.; FIGUEIREDO, V. F. Tecnologias de informação e comunicação nas práticas pedagógicas em escola pública: desafios na implementação e gestão. Humanidades \& tecnologia em revista, p. 24, 2018.

MATA, V. d. S. et al. Indústria 4.0: a revolução 4.0 e o impacto na mão de obra. Revista de Ciências Exatas e Tecnologia, v. 13, n. 13, 2018.

NETO, M. et al. Robótica educacional uma ferramenta para ensino de lógica de programação no ensino fundamental. In: Anais do Workshop de Informática na Escola. [S.1.: s.n.], 2018. v. 24, p. 315.

PINTO, S. C. C. d. S.; MATTOS, M. S. A programação de jogos como um instrumento motivador da aprendizagem. Revista Espaço Pedagógico, v. 26, n. 2, p. 370-394, 2019.

RODRIGUES, S.; ARANHA, E.; SILVA, T. R. Computação desplugada no ensino de programação: Uma revisão sistemática da literatura. In: Brazilian Symposium on Computers in Education (Simpósio Brasileiro de Informática na Educação-SBIE). [S.1.: s.n.], 2018. v. 29, p. 417.

SOARES, L.; CAVALCANTI, E. R. et al. Avaliação experimental do robomind no ensino de programação com estudantes do curso técnico em informática integrado ao ensino médio. In: Brazilian Symposium on Computers in Education (Simpósio Brasileiro de Informática na Educação-SBIE). [S.1.: s.n.], 2018. v. 29, p. 288.

TORCATE, A. S. et al. A inserção de computação como disciplina no ensino fundamental: Desafios e conquistas em estágio supervisionado. In: SBC. $26^{\circ}$ Workshop sobre Educação em Computação (WEI 2018). [S.1.], 2018. v. 26. 